\title{
Conflicting roles of researchers in sustainability transitions: balancing action and reflection
}

\author{
Ellen Bulten ${ }^{1} \cdot$ Laurens K. Hessels $^{2,3}$ (D) $\cdot$ Michaela Hordijk $^{4} \cdot$ Andrew J. Segrave $^{5}$
}

Received: 19 June 2020 / Accepted: 3 March 2021 / Published online: 18 March 2021

(c) The Author(s) 2021

\begin{abstract}
Process-oriented transdisciplinary research is generally seen as a promising approach to facilitate sustainability transitions. This type of research requires new participatory roles for researchers. These new roles may conflict with traditional, more academic roles that researchers often maintain next to their new roles. Using the Dutch transdisciplinary Knowledge-Action Programme on Water (KAP Water) as a case study, we highlight tensions that researchers adopting these new roles experience. We have observed both practical and more fundamental tensions between roles of researchers in process-oriented sustainability research. In particular, it proved difficult to combine more engaged roles, where researchers are involved in dialogues for change, with knowledge-oriented roles, where researchers focus on knowledge provision and are further removed from 'real-world action'. Tensions arise from three sources: (1) researchers' self-perception and expectations; (2) expectations from transdisciplinary partners, funders and researchers' home institutions; and (3) societal convictions about what scientific knowledge is and how it should be developed. This paper contributes to the literature by enhancing the understanding of the interactions and tensions between the roles of researchers in transdisciplinary research.
\end{abstract}

Keywords Roles of researchers $\cdot$ Sustainability transitions $\cdot$ Process-oriented $\cdot$ Transdisciplinary research $\cdot$ Tensions

\section{Introduction}

In response to pressing sustainability issues in a number of domains such as energy supply, water supply, transportation and agriculture, there is growing interest in transitions towards sustainability (Frantzeskaki et al. 2012; Grin et al.

Handled by Osamu Saito, Institute for Global Environmental Strategies, Japan

Laurens K. Hessels

1.k.hessels@cwts.leidenuniv.nl

1 Wageningen Plant Research, Wageningen University and Research, Edelhertweg 1, 8219 PH Lelystad, The Netherlands

2 Centre for Science and Technology Studies, Leiden University, P.O. Box 905, 2300 AX Leiden, The Netherlands

3 Rathenau Instituut, P.O. Box 95366, 2509 CJ Den Haag, The Netherlands

4 Amsterdam Institute of Social Science Research, University of Amsterdam, P.O Box 15629, 1001 NC Amsterdam, The Netherlands

5 KWR Water Research Institute, P.O. Box 1072, 3430 BB Nieuwegein, The Netherlands
2010; Markard et al. 2012). Sustainability transitions deal with 'wicked problems' that persist over time and require a fundamental change of culture, structure and practices in order to achieve a new, sustainable system (Frantzeskaki and De Haan 2009). Wicked problems are characterised as being non-predictable and 'open ended' emergent phenomena with non-linear dynamics. Wicked problems have no clear-cut definition because too many factors underlying the problem influence each other. Numerous possible explanations exist and since every attempt to address a wicked problem affects the underlying complex system: each intervention affects the initial problem and can make it even more complex (Klein 2004; Menken and Keestra 2016; Scholz and Steiner 2015b). Ambiguity exists between the perceptions of the various actors who are working to address wicked problems, meaning that there are divergent understandings of both the problems and the solutions (Segrave 2014).

Given the complexity, uncertainty and ambiguity of the problems, the sustainability transitions to address them crucially depend on inputs from scientific knowledge. However, the typical mono-disciplinary and linear organisation of academic knowledge production tends to limit the contribution of science to incalculable and uncertain transition 
processes, making it hard for academic knowledge production to match the needs of transition processes. In order to facilitate societal change, researchers cannot rely on a knowledge-first approach, they should also actively participate in change processes. This has been termed a processoriented approach to sustainability science (Miller 2013). Although the former approach regards the scientist purely as a provider of knowledge, a process-oriented approach sees a more engaged role for the scientist in also being involved in dialogues for change. Process-oriented sustainability science can be regarded as a manifestation of transdisciplinarity, a collaborative mode of knowledge production with contributions from both researchers and practitioners (Hadorn et al. 2006; Lang et al. 2012; Wiek and Lang 2016) and a critical and self-reflexive research approach that relates societal with scientific problems (Jahn et al. 2012).

Process-oriented approaches towards sustainability transitions require new roles and activities for researchers that go beyond traditional roles and activities (Hilger et al. 2018; Loorbach 2010; Pohl et al. 2010; Wittmayer and Schäpke 2014). Apart from acting as a traditional provider of knowledge, researchers also need to function as knowledge brokers, process agents and change agents (Wittmayer and Schäpke 2014). Funders and programme managers tend to have unrealistic expectations of researchers in transdisciplinary projects, resulting in overburdening of researchers (Pohl and Hadorn 2007). Moreover, there is a paradoxical tension in transdisciplinarity being simultaneously part of and separate from traditional research contexts (Polk 2015). This tension is also evident in what is expected from transdisciplinary processes. Such processes are supposed to have a socially robust orientation and lead to solutions which are both socially accepted as well as science-based and stateof-the-art (Scholz and Steiner 2015a). 'Science-based state of the art' seems to refer to more traditional understandings of science, whereas 'socially robust and accepted solutions' gear more towards what can result from collaborations. In this contribution, we wish to highlight this tension in process-oriented sustainability research and reflect on possible ways to resolve this.

Although earlier research has provided typologies of new tasks and roles for researchers (Adelle et al. 2019; Wittmayer and Schäpke 2014) and has identified some factors that influence how researchers choose to adopt certain roles (Hilger et al. 2018), there is still a limited understanding of the interactions and tensions between the different roles of researchers in transdisciplinary research. This paper aims to address this gap. Because our case study takes a societal rather than a technical approach by focussing on governance, our analysis will focus on social scientists. We assume that the roles and tensions experienced by researchers are likely to differ between disciplines. The aim of this paper, therefore, is to unravel how social-scientific researchers deal with various tensions in their roles within transdisciplinary sustainability research to make a valuable contribution to sustainability transitions.

We use the Dutch Knowledge-Action Programme on Water as a case study. First, we introduce a theoretical and analytical framework describing roles of researchers involved in process-oriented sustainability research. Second, we present our methodology including a description of the Knowledge-Action Programme on Water. Third, we present the results of our empirical study. In conclusion we discuss the implications of our results.

\section{Theoretical framework}

\section{Transdisciplinarity and sustainability programmes}

Innovation and transition processes that aim to solve complex societal problems require a heterogeneous group of stakeholders to be involved, which simultaneously increases the ambiguity of the problem definition (Dewulf et al. 2005; Regeer 2009; Schut et al. 2013). Transdisciplinary, processoriented research is suggested as a promising approach to address sustainability challenges and develop sustainable solutions (Hadorn et al. 2006; Lang et al. 2012). Transdisciplinary research is characterised by co-production of knowledge by different scientific disciplines and non-scientific actors from domains, such as business, government and civil society (Lang et al. 2012; Stock and Burton 2011). Transdisciplinary processes are often conceptualised in three phases: (i) forming a common research object, (ii) producing new knowledge and (iii) evaluating new knowledge for its contribution to both societal and scientific progress (Jahn et al. 2012). To guarantee that research reflects the complexity and diversity of sustainability challenges, it is important to include all relevant actors, visions and interests in transdisciplinary sustainability programmes (Hadorn et al. 2006). Involvement of non-scientific actors in research programmes has indeed been found to result in knowledge that is more useful in practice (Jolibert and Wesselink 2012; Walter et al. 2007). Becker (2002) describes transdisciplinary sustainability research as a highly interactive process between different researchers and social actors, where new phases are entered and relationships change continuously. In this context, Wiek et al. (2012) describe the development of sustainability science in a tension between a descriptive-analytical and a transformational mode. Although the first focusses on analysing problems, the second mode focus on research to find practical solutions to these problems. A typical problem in sustainability and transdisciplinary projects is finding a balance between understanding a problem in its reallife context and working towards its transformation on the one hand and contributing to a common body of theoretical 
knowledge on the other hand. Miller distinguishes between a 'knowledge-first' approach, in which researchers act primarily as a knowledge provider and a process-oriented approach in which researchers also participate in "establishing, facilitating and participating in mechanisms or dialogues for change"' (Miller 2013). This paper focuses on processoriented research.

Although transdisciplinary research is often suggested as a suitable approach in sustainability literature, there are also barriers and challenges associated with it. Because the principles of transdisciplinary research do not readily match with the institutional context of academic research, it requires protection in the form of nurturing, shielding or empowerment (Boon et al. 2019). There is a large body of literature elaborating on the barriers for transdisciplinary research. Brouwer et al. (2017) summarise these barriers by differentiating between methodological and epistemological barriers, social and political barriers and institutional barriers. These barriers can be expected to be even more powerful in the case of process-oriented research. On the epistemological level, academic researchers experience difficulties in transcending disciplinary boundaries and recognising the relevance of experiential knowledge (Benard and de CockBuning 2014). On the social level, it can be difficult to overcome cultural differences in the norms and values of research versus practice (Mollinga 2009). Moreover, various conflicts can occur when collaborations involve different partners, reflecting the different priorities of the research partners and of the practitioners (Kloet et al. 2012), different expectations among the partners (Boon et al. 2014) or different problem definitions among actors (Hegger et al. 2012). On the institutional level, transdisciplinary research has been shown to be less rewarding in terms of publications in high impact journals (Rafols et al. 2012) career advancement (Van Rijnsoever and Hessels 2011), and funding acquisition (Bromham et al. 2016). Strategies to overcome the various challenges include balanced team composition (Boon et al. 2014), smart programme design (Hessels et al. 2018) and tailored quality criteria (Jahn and Keil 2015). The current paper deals with the struggles of individual researchers in dealing with the demands and expectations of different actors.

\section{Roles of researchers in sustainability transitions}

Taking a process-oriented transdisciplinary approach in sustainability science has implications for the role of the researcher (Scholz 2017). Roles are socially constructed and are negotiated during the process, they can change over time because of process dynamics. Roles can be purposefully adopted, but can also gradually develop often in an interplay between programme necessities and personal characteristics of the researcher (Hilger et al. 2018; Wiek 2007; Wittmayer et al. 2017; Wittmayer and Schäpke 2014). The integration of non-scientific actors and knowledge in research implies different expectations about the activities of researchers. Next to creating new scientific knowledge, scientists are now also expected to contribute to activities such as facilitating collective learning processes and bringing sustainability into practice (Loorbach 2010; Pohl et al. 2010; Wittmayer and Schäpke 2014). Moreover, both science and society call for researchers to recognise and accept their social responsibility for the consequences of the application of their research (Cornell et al. 2013). This may also include active participation in sustainability transitions, which in turn implies that researchers can be invited to take up a role in processes initiated by others, for instance as catalysts or even activists (Scholz 2017) According to the principles of action research, intervening in the object of research can serve both as an impact strategy and as a strategy to acquire valuable insights (Kemmis 2009; Zuiderent-Jerak 2015). This double motivation is similar to the goals of design science research, which aims both to improve the environment by the introduction of new and innovative artefacts and to build a systematic knowledge base (Hevner 2007). Such process-oriented research also requires different competencies of researchers. Wiek et al. (2011) synthesised five key competences that are needed to address complex sustainability challenges: systems-thinking competence, anticipatory competence, normative competence, strategic competence and interpersonal competence. In order to successfully co-create knowledge and action for sustainable development, these five competencies should be integrated and combined with each other.

This paper deals in particular with process-oriented research practices in which researchers do not only produce and provide knowledge to support sustainability transitions, but in which they intend to also actively contribute to systemic change. This results in what Wiek (2007) calls a 'third epistemic way' of doing joint research that comes with four general challenges that add to the complexity of knowledge co-creation: confounded agenda's, separate data philosophies, reluctance to face exposure and co-existing values (Wiek 2007). Adelle et al. (2019) similarly created a framework to clarify the role of the researcher in co-creation processes, differentiating between tasks for researchers during problem exploration (e.g. identifying and clarifying diverging views and values), problem puzzling (e.g. gathering ideas) and problem solving (e.g. finding realistic pairings between problems and solutions).

New expectations of sustainability researchers come with specific challenges for researchers, in addition to the barriers to transdisciplinarity listed above. Wittmayer and Schäpke (2014) have identified four key issues for researchers in process-oriented approaches to sustainability research: ownership, sustainability, power and action. They relate these four issues to five corresponding roles of researchers in transdisciplinary sustainability research. These roles 
reflect how researchers deal with the four key issues: reflective scientist, process facilitator, knowledge broker, change agent and self-reflexive scientist (Wittmayer and Schäpke 2014). Building on this typology, the current paper aims to enhance the understanding of the interactions and tensions between these different roles, which remain underexplored in the paper by Wittmayer and Schäpke.

Hilger et al. (2018) have found that researchers adopt non-conventional (i.e. more engaged) roles under certain conditions: (1) when being pressured to carry out real-world action; (2) when researchers work with practice partners who have fewer resources such as time, staff and financial resources; (3) when there is lack of a functional project group. Researchers are likely to adopt the role of change agent when these conditions occur in conjunction. Hilger et al. (2018) also found that the role of self-reflexive scientist was often chosen as a 'retreat' option when it was not possible or desired to take on any of the other roles.

\section{Analytical framework}

Our analytical framework strongly builds on the work of Wittmayer and Schäpke (2014) and Hilger et al. (2018), but we have chosen to formulate more precise definitions, that differ at some points from the original terminology. We conceive the four issues introduced by Wittmayer and Schäpke as questions that need to be addressed in order for a processoriented programme to succeed. If programme participants do not agree about these issues, expectations of the roles and contributions of researchers will vary, creating uncertainty and ambivalence for the researchers. For the first three issues we use the definitions provided by Wittmayer and Schäpke; for the fourth we have formulated our own question similar to the other three.

- Ownership: Who owns (parts of) the problem, the process, its outcomes and its possible continuation?

- Sustainability: What is the dominant understanding of possible pathways to achieving sustainability?

- Power: Who determines the contours of the space for societal learning and sets its direction?

- Action: How to balance action and real-world change on the one hand with reflection and analysis on the other? This question is slightly more precise than the formulation of Wittmayer and Schäpke who argue that 'researchers actively facilitate research processes, which are aimed at fostering action or real-world change (...)' but do not define the dilemma how to balance action and reflection that researchers face as a result.

Based on an analysis of recent literature we have adapted the sets of different activities that characterise different possible roles in the process in Table 1. The delineations between the different roles are not as clear cut as the table may suggest. As indicated, these roles are formed, negotiated and can change during the research process, both purposefully and in reaction to process dynamics. We have ordered the potential roles with respect to the level of engagement, in which the traditional researcher (knowledge-oriented) at one end of the spectrum works 'disengaged from practice', whereas the transition leader takes on an engaged role and is deeply immersed in real life action (action-oriented). It can be expected that more engaged forms of research can lead to stronger experience of the tension of being simultaneously part of and separate from traditional research contexts (Polk 2015), as well as of potential overburdening (Pohl and Hadorn 2007).

\section{Methods}

\section{Our case: the knowledge-action programme on water (KAP Water)}

Our case study is located in the Netherlands, a country mostly below sea level where water management is essential to national security. In addition, many of the envisaged transitions for the Netherlands (e.g. climate adaption, renewable energy, circular economy, reversal of biodiversity loss) have serious consequences for water management. Our case addresses current urban sustainability challenges in the context of ongoing developments in the Metropolitan Region of Amsterdam.

The Knowledge-Action Programme on Water (KAP water) was initiated in 2015 , following a project proposal drafted by a policy entrepreneur from the water authority of Amsterdam (Waternet) and an action researcher from an applied water research institute (KWR), submitted to a member of the executive board and the general administrative body of the water authority. Science, policy and practice therefore combined forces from the outset. In 2016, the local universities (Vrije Universiteit Amsterdam and the University of Amsterdam) joined the KAP Water team, bringing models of how to approach (knowledge) co-creation.

In the Dutch water sector, the dominant approach used for facilitating innovation is to demonstrate and test new technologies in pilot projects. Over the past 15 years it has become increasingly obvious, however, that these pilots will not bring about the necessary transitions on their own, because pilots are generally technology focussed and tend to not sufficiently take social, political, legal and economic factors into consideration. Moreover, the knowledge system was failing to support policy entrepreneurs in their endeavours to achieve the intended transitions. In this context, KAP water was initiated and grew. 
Table 1 Potential roles and typical activities in process-oriented sustainability science

\begin{tabular}{|c|c|}
\hline Role & Typical activities \\
\hline $\begin{array}{c}\text { Traditional researcher } \\
\text { (reflective scientist) }\end{array}$ & $\begin{array}{l}\text { Provide scientific knowledge on the basis of analysis, validated by the respective discipline, to inform decision making } \\
\text { (Miller 2013; Pohl et al. 2010; Wittmayer and Schäpke 2014) } \\
\text { Investigate application-oriented knowledge (legislation, best practices, etc.) (Hilger et al. 2018) } \\
\text { Analyse dynamics, actors and actions (often ex post) (Wittmayer and Schäpke 2014) } \\
\text { Analyse outcomes (Wittmayer and Schäpke 2014) } \\
\text { Reflect on interventions, evaluates disengaged from praxis (Hilger et al. 2018) } \\
\text { Deconstruct problems into solvable parts (Adelle et al. 2019) } \\
\text { Overlay existing concepts on problem narratives and frames (Adelle et al. 2019) }\end{array}$ \\
\hline Self-reflexive scientist & $\begin{array}{l}\text { Write observation protocols and research diaries (participate and observe) (Hilger et al. 2018) } \\
\text { Reflection with regard to internal and external power-dynamics (Wittmayer and Schäpke 2014) } \\
\text { Reflection on own normative orientation (Wittmayer and Schäpke 2014) } \\
\text { Provide feedback to the other researchers in order to facilitate reflection about their interactions with practitioners (Hoes } \\
\text { et al. 2008) }\end{array}$ \\
\hline Knowledge broker & $\begin{array}{l}\text { Synthesise academic knowledge and make this accessible for practitioners and vice-versa (Miller 2013) } \\
\text { Provide space for critical reflection (Wittmayer and Schäpke 2014) } \\
\text { Mediate different perspectives (Wittmayer and Schäpke 2014) } \\
\text { Match experts and stakeholder groups (Schut et al. 2013) } \\
\text { Translate, interpret and connect knowledge to different audiences (Adelle et al. 2019; Maag et al. 2018) } \\
\text { Link scientific analysis to public debate (Adelle et al. 2019) } \\
\text { Find realistic problem-solution couplings (Adelle et al. 2019) }\end{array}$ \\
\hline Process facilitator & $\begin{array}{l}\text { Initiate and facilitate the learning and design process and experiment (Maag et al. 2018; Wittmayer and Schäpke 2014) } \\
\text { Organise and prepare work sessions } \\
\text { Locate, select and invite participants (Adelle et al. 2019; Wittmayer and Schäpke 2014) } \\
\text { Encourage expressions of different viewpoints (Wittmayer and Schäpke 2014) } \\
\text { Provide space for critical reflection and deliberation (Hilger et al. 2018; Pohl et al. 2010) } \\
\text { Knowledge integration (Jahn et al. 2012) }\end{array}$ \\
\hline $\begin{array}{l}\text { Transition participant } \\
\text { (change agent) }\end{array}$ & $\begin{array}{l}\text { Participates in process that aims to address real life problems (Hilger et al. 2018; Wittmayer and Schäpke 2014) } \\
\text { Actively intervene in system innovation (Wittmayer and Schäpke 2014) }\end{array}$ \\
\hline Transition leader & $\begin{array}{l}\text { Actively intervene in system innovation by motivating and empowering participants to lead their own process (Witt- } \\
\text { mayer and Schäpke 2014) } \\
\text { Recognise the implications of current levels of capacity while also building capacity (Adelle et al. 2019) }\end{array}$ \\
\hline
\end{tabular}

The motto of KAP Water (2016-2019) ${ }^{1}$ is: Organising Innovatively, Together. The aim is to support the intended transition to the circular, resilient cities of the future with knowledge development and knowledge valorisation embedded in planning and design processes. With scientifically sound and broadly supported knowledge, the decisions and actions of the government and partners are better substantiated. The necessity to balance 'science based' and 'socially accepted' knowledge (Scholz and Steiner 2015a) was thus evident from the very beginning of the programme.

Much attention was paid to 'asking the right questions', so most of 2016 was spent on preparing a knowledge-action agenda, which was validated and supported by relevant stakeholders, and peer-reviewed by scientists. This phase was financed by the water authority of Amsterdam (Waternet), with in-kind contributions from the other partners and

\footnotetext{
1 The programme has been extended for the term 2020-2023 and now has a broader scope and includes cases in other parts of The Netherlands. However, at the time of our data collection the programme was limited to Amsterdam. For more information on the programme, visit the website: https://kennisactiewater.nl
}

co-funding from Amsterdam Water Science and KWR. The outcome was a programme with four work-packages (WPs), as shown in Table 2. WP1 and WP3 developed mostly along the lines of reflective science and knowledge brokering: systematisation and synthetisation of existing knowledge and application-oriented knowledge, with a disengagement from praxis. WP2 developed into a strongly action-oriented project, with a co-creation trajectory at its centre. WP4 was enacted in light of one of the core-objectives of the programme: creating a vibrant knowledge action network consisting of governors, practitioners and scientists, that would spur the innovation in water governance in the Amsterdam Metropolitan Region. See our supplementary material for more details.

The specific knowledge demand in KAP Water was to support the co-creation of innovative governance arrangements that enable a resilient, sustainable and circular water cycle. WP leaders were chosen according to the expertise of the various institutions involved. WP leaders were all researchers with a $\mathrm{PhD}$ degree, since the executive board and the general administrative body of the water authority asserted that the scientific rigour and "neutrality" of 
Table 2 Work packages and goals of the knowledge-action programme on water 2016-2019

\begin{tabular}{ll}
\hline Work package & Goals \\
\hline WP1: governance strategies & $\begin{array}{c}\text { Provide policy entrepreneurs in the current co-creation projects with action } \\
\text { perspectives and help the elected members of the executive board of the water } \\
\text { authority to make more informed decisions }\end{array}$ \\
$\begin{array}{ll}\text { Wugment co-creation projects with action researchers to: (1) unlock knowledge } \\
\text { for the policy entrepreneurs about issues that are crucial to their designs; (2) }\end{array}$ \\
$\begin{array}{l}\text { Identify and articulate knowledge needs to prioritise themes and set agendas } \\
\text { in the science system; (3) Record knowledge and the learning process from } \\
\text { individual cases to help others who follow (4) Give direction to the design } \\
\text { and learning process (e.g. using a specific reflexive design methodology) }\end{array}$ \\
$\begin{array}{l}\text { Identify opportunities and bottlenecks for innovative governance, including } \\
\text { innovative business cases for providing water services and with special atten- } \\
\text { tion to the division of responsibilities and risks. The underlying goal is to } \\
\text { make options clearer for decision makers }\end{array}$ \\
$\begin{array}{l}\text { Provide methods for fruitful knowledge exchange based on existing literature } \\
\text { and facilitate a reflexive and responsive approach in the programme. The end } \\
\text { goal is to strengthen the local knowledge-action system (science-policy-prac- } \\
\text { tice interface) in Amsterdam to help all parties involved to learn, exchange } \\
\text { experiences, formulate new (research) questions and thus enable the intended } \\
\text { transitions }\end{array}$ \\
\hline
\end{tabular}

knowledge was paramount. At the same time, innovators and policy entrepreneurs in the co-creation processes were given priority in defining the thematic focus of the work. The WP leaders and programme leader, together with two policy entrepreneurs from the water authority of Amsterdam, formed a core team who coordinated activities, such as workshops to stimulate dialogue between policy makers, practical innovators and scientists. The co-creation trajectories involved (and were owned by) participants from various public organisations. For example, in the pilot that focussed on opportunities for integrating asset management across the water and energy sectors, the municipality, water authority, and energy network manager were at the table with researchers as reflexive scientists, who took on various combinations of the roles listed in Table 1.

\section{Research strategy}

This article builds on the results of WP4, and partly results from the structured discussions on the different roles of researchers held within WP4. All four authors have been part of KAP water, but in different phases of the programme, with different levels of engagement and in different roles. The lead author of this article was a relative outsider and performed the role of reflective scientist. The other three authors formed part of the core team, responsible for WP2, WP4 and overall responsibility for the programme respectively. This article therewith is a thorough self-reflexive exercise, but simultaneously based on a series of interviews and document analysis mainly performed by the lead author. We specifically reflected on our own normative assumptions on the role of research(ers) in process-oriented sustainability research (Wittmayer and Schäpke) and scrutinised the ways in which we produced and used knowledge and methodologically challenged "how science itself deals with the tension between its constitutive pursuit of truth and the ever increasing societal demand for the usefulness of its results" (Jahn et al. 2012).

WP4 started with an analysis of the existing knowledge action network, performed as reflective science. ${ }^{2}$ In a second round of analysis a relative outsider (lead author) interviewed researchers as well as societal actors (i.e. from the domains of policy, practice and governance) who were involved in the programme. Additionally, we analysed internal documents and (web) publications ${ }^{3}$ and drew from observations by the authors during meetings and workshops (not fully documented). Table 3 provides an overview of the interviews. The semi-structured, in-depth interviews involved questions related to topics such as knowledge co-creation, the role of the interviewee in the knowledge-action network and the interaction of knowledge and action in the programme. By using a flexible interview guide, we were able to tailor the questions to the position of the actors in each of the four domains. The interview series in 2017 focussed on policymakers and practitioners, in order to investigate

\footnotetext{
2 This analysis resulted in a Master's thesis report by van Splunter (2017), titled: "Strengthening the knowledge action system of circular and sustainable water governance in Amsterdam". This thesis is available at https://kennisactiewater.nl

3 This included (blog) reports about workshops or meetings and a document describing the approach of the KAP Water programme (titled:"programma-aanpak voor vernieuwing in water governance"). These documents are publicly accessible at https://kennisactiewater.nl
} 
Table 3 Interviews conducted in 2017, 2018 and 2019 with actors who were involved in the Knowledge-Action Programme on Water from the domains of research, governance, policy and practice

\begin{tabular}{|c|c|c|c|}
\hline & 2017 & 2018 & 2019 \\
\hline Research & 1. Researcher system change & $\begin{array}{l}\text { 8. Researcher strategy development } \\
\text { 9. Researcher governance } \\
\text { 10. Researcher value creation } \\
\text { 11. Researcher system change } \\
\text { 12. Researcher risks and responsibilities }\end{array}$ & $\begin{array}{l}\text { 23. Researcher } \\
\text { strategy develop- } \\
\text { ment } \\
\text { 24. Researcher } \\
\text { reflexive moni- } \\
\text { toring } \\
\text { 25. Researcher } \\
\text { system change } \\
\text { 26. Researcher } \\
\text { knowledge co- } \\
\text { creation } \\
\text { 27. Researcher } \\
\text { system change } \\
\text { 28. Researcher } \\
\text { value creation }\end{array}$ \\
\hline Governance & & $\begin{array}{l}\text { 13. Water Board (executive) } \\
\text { 14. Water Board (general) } \\
\text { 15. Water Board (general) } \\
\text { 16. Water Board (general) }\end{array}$ & \\
\hline Policy & $\begin{array}{l}\text { 2. Waternet (see footnote 4) } \\
\text { 3. Waternet } \\
\text { 4. Municipality of Amsterdam }\end{array}$ & $\begin{array}{l}\text { 17. Waternet } \\
\text { 18. Municipality of Amsterdam } \\
\text { 19. Waternet } \\
\text { 20. Waternet }\end{array}$ & \\
\hline Practice & $\begin{array}{l}\text { 5. Engineer } \\
\text { 6. Business owner } \\
\text { 7. Business owner }\end{array}$ & $\begin{array}{l}\text { 21. Consultant electrical power } \\
\text { 22. Consultant smart grids }\end{array}$ & \\
\hline
\end{tabular}

their expectations and experiences with the programme. In the second series of interviews (2018), conducted by the lead author, actors from all domains (i.e. research, governance, policy, practice) involved in the programme reflected on their experiences in the programme so far. Interviewees in this series were sampled by selecting actors who were, at that moment, actively involved in the co-creation sessions of KAP Water, to be able to reflect with them on their experiences in the programme. The set of interviews in 2019 specifically focussed on a reflection by researchers regarding their role as a researcher and challenges they had to deal with being involved in the programme. All researchers who played a substantial role in KAP Water were interviewed during this series (most interviewees overlapping with those interviewed in the 2018 series).

Interviews from the 2017 and $2018{ }^{4}$ series were all recorded and transcribed verbatim. Interviews from the 2019 series were either transcribed immediately during the interview itself or responded to in writing by the interviewee. Interview transcripts were then coded using Atlas. ti software (qualitative data analysis). Coding was first done deductively, using a codebook based on our theoretical and

\footnotetext{
${ }^{4}$ Waternet is a governmental organisation in Amsterdam focusing on drinking water supply, sewage systems and water management.
}

analytical framework (Hsieh and Shannon 2005): we clustered codes in code croups around theoretical themes using the code groups 'knowledge co-creation', 'key issues for researchers', 'reflexivity', 'roles of researchers', 'transdisciplinarity' and 'type of knowledge question'. Then, we coded the data inductively, adding codes that emerged from reading and re-reading the raw data to the existing code groups (Mayring 2004; Thomas 2003), using an interpretive and comparative approach. Analysis of the interview transcripts was done in an iterative process of multiple rounds of coding (Charmaz and Belgrave 2012), going back to previously coded transcripts to integrate new (inductive) codes and to confirm/adapt previous coding.

Our results section is firstly based on the analysis of the interviews $(n=28)$, enriched with internal document analysis and observations during meetings and workshops. Note taking during workshops and other meetings was not done systematically, mainly due to lack of planning and time and in some cases because no-one was explicitly assigned a role as note-taker. Because of this lack of systematic note taking, these sources are subject to biased interpretation of researchers. We therefore used those sources and observations only complementary to the analysis of the interviews. Additionally, we asked researchers involved in KAP Water (but not involved in the writing of this article) to reflect on 
our manuscript and indicate whether they recognised our findings. We integrated their reflections in this article.

\section{Results}

In this section we first discuss how the key issues were addressed within KAP Water as well as possible tensions researchers experienced in addressing these questions (Sect. 4.1). In Sect. 4.2 we discuss the interplay of roles that researchers adopted in KAP Water when addressing these questions.

\section{Issues and roles}

Ownership: Who owns (parts of) the problem, the process, its outcomes and its possible continuation?

Practitioners, public sector managers, policy officers and researchers in KAP Water felt they had a common task in working towards innovative water governance. While there was willingness to join efforts and work on solutions, none of the involved parties felt they were responsible for the problem of adjusting water governance to new challenges in water management. The municipality of Amsterdam was often named as a coordinating party responsible for realising the outcomes of their collaboration. The municipality is the leading party. (...) in the end, they are going to do it and they will make the final decision. We want to do our part, but they are in the driver's seat (Governance). The municipality recognised that they are an important party that can take a coordinating role in implementing solutions, but they were also still searching for their position in the process and who should be responsible for what. We used to have sectoral owners. (...) they all interact with each other, but who is responsible overall? (Policy).

Researchers, on the other hand, were seen as owner of the process by actors involved in the co-creation process, and researchers also took on this responsibility by acting as process facilitators in the co-creation sessions. In line with the analysis by Hilger et al. (2018), the adoption of the role can be partly explained by the limited resources available for the programme. With regard to ownership, researchers did not necessarily experience tensions regarding their role as a researcher, but rather between who they felt should be the owner (i.e. cooperating organisations in the programme) and those who acted like the owners (i.e. the core team of the cocreation trajectory). Researchers felt ambivalent with regard to the division of responsibility, resulting in researchers initially taking responsibility for the process, but trying to hand back responsibility later on in the programme. Ambiguity around problem ownership made it difficult to move forward. Researchers participated in the co-creation sessions as process facilitators by (co)organising the sessions. As transition participants, researchers positioned themselves next to the other participants, working together to find solutions for a circular water cycle.

Sustainability: What is the dominant understanding of possible pathways for sustainability?

Sustainability was not a contested topic in KAP Water, in the sense that participants from all organisations saw the need for change towards sustainability and shared a sense of urgency to change current water governance. In the cocreation sessions all participants expressed a personal drive to advance systems transformation through their work, although the best way to reach sustainable water governance was subject to discussion. An example of a sustainability issue was the discussion whether solutions should be centralised or decentralised. This was an ongoing discussion that returned throughout the process.

In discussions around sustainability, participants expected researchers to provide answers about 'best' sustainable solutions. However, researchers felt that this was not their task because they wanted to explore possible sustainable solutions together, in a co-creation process. Nevertheless, in their role as traditional researcher researchers operationalised sustainability concepts and studied possible sustainable solutions, for example with regard to multiple value creation. During co-creation sessions, researchers translated and shared research results in their role as knowledge broker and process facilitator. Because exploring different sustainable solutions was part of the programme's set-up, researchers did not experience sustainability as a major issue in KAP Water. It goes without saying that we work with different perspectives, so there are also different definitions of sustainability (Research). Finally, researchers observed that within KAP Water participants created and exchanged a lot of knowledge about problems around water governance and possible solutions, but not about how to implement these solutions and move from future visions to the desired scenario. In other words, they focussed on target knowledge rather than transformation knowledge (Pohl and Hadorn 2007).

Power: Who determines the contours of the space for societal learning and sets its direction?

The network of actors (researchers, policy officers, governors, practitioners) formed around KAP Water included different norms and values in relation to collaboration and knowledge production (Mollinga 2009). One of the outcomes of the programme is strengthened relationships within the network and closer relationships between participants. In practice you create networks of people who get to know each other (Practice). As process facilitators researchers facilitated the learning process by posing thought-provoking statements and questions and strategically pairing participants with each other. As traditional researchers, researchers made assumptions explicit and voiced observations with 
participants to create awareness. I posed the slogan 'with business as usual we are not going to make it'. (...) Statements like this really get people moving. It ensured that central people joined us (Research).

Researchers experienced several tensions in relation to power dynamics in KAP Water, such as a mismatch between needs of the client who funded the programme (interaction, networking) and needs of the researcher (deepening learning process through scientific analysis). This resonates with earlier analyses of transdisciplinary programmes that found diverging expectations and incentive structures between researchers and stakeholders (Boon et al. 2014; Kloet et al. 2012). Related to this, several participants have experienced a lack of clarity about who got to decide the course of the programme. Because actors with the authority (managing directors of the participating organisations) to make final decisions were not present at the co-creation sessions, the teams felt that processes of change were delayed. Processes go slowly, a lot more slowly than we would like. We feel that power is exercised way too little (Research). As transition leaders, researchers helped shape meetings between the teams and 'authoritative' actors to speed up both the decision making process and the innovation process.

Action: How to balance action and real-world change on the one hand with reflection and analysis on the other?

Action was a central part of the co-creation sessions where actors from the domains of practice, policy, governance and research collaborated to work towards innovative water governance in Amsterdam. Participants from practice, policy and governance appreciated the fact that KAP Water adaptively developed alongside developments 'in the field'. However, for researchers it was difficult keep up with everything that happened in practice while simultaneously maintaining the continuity of the programme and conducting relevant research to answer questions that arose within the programme.

Researchers involved in the co-creation sessions in their roles as process facilitator and transition participant struggled to find a balance between participating on the one hand and documenting the learning process on the other hand. We are so busy 'doing' that we fail to document and systemise the learning process (Research). Experience with this way of working seems an important factor to tackle this issue. This may relate to the key competences for process-oriented research proposed by Wiek et al. (2011). Acting in a system innovation requires continuously switching between (...) what happens in your environment and the broader context. That requires exercise (Research). On the other hand, researchers who were not involved in the co-creation sessions often took on a role as traditional researcher, developing new knowledge based on learning questions raised in the co-creation sessions. While KAP Water focusses both on knowledge production (through research, dissemination, etc.) and action (by working with a diverse network of stakeholders on real-life change), knowledge and action were not always integrated well. Some researchers felt that decision makers did not take their research results sufficiently into account, while decision makers argued knowledge did not sufficiently connect to their reality. WP4 provided the reflection space to discuss this tension, becoming more aware of the different time-cycles of reflective research vis-à-vis practice. These discussions did not solve the problem, but did stimulate researchers to sometimes more consciously switch roles when practice needed it. For instance, by quickly reviewing documents from practice and providing application-oriented knowledge, instead of awaiting posthoc analysis.

\section{Interplay of roles}

Researchers in KAP Water frequently changed and combined roles during the research process. Researchers experienced their role as complex and multi-faceted and they often had to adopt multiple roles at the same time. In their search for the right role to adopt, they often struggled with different expectations from themselves and from others. This relates to the social construction and negotiation of the researchers' identity (Swann Jr and Bosson 2008). Participants in KAP Water had implicit and/or explicit ideas about what the role of the researcher should be in the programme. These expectations ranged from providing 'state of the art', knowledge based input (e.g. disseminate knowledge, document knowledge) to more action-based, socially relevant input (e.g. facilitate the design process, create public support).

In line with earlier studies (Boon et al. 2014; Kloet et al. 2012), these expectations were very diverse and did not necessarily align with the expectations of the researcher. For example, researchers did not always have the answer to pressing questions while participants expected the researcher to provide these answers. The problem owner expects different things from me than what I think is good for the process. They expect me to organise the design process, not that I research it (Research). Participants expected researchers to answer the question which solution is most sustainable, but that is not so clear cut. Although the expectations of participants match the roles of researchers as defined in this article, the emphasis or interpretation of roles could differ from the expectations of researchers themselves. For example, researchers did not see themselves solely as process facilitator, but rather as combining this with other roles (e.g. knowledge broker and/or transition participant) while participants expected researchers to commit themselves to organise and facilitate the process. Researchers were under pressure 'to carry out real-world action', in a way similar as in the real-world labs analysed by Hilger et al. (2018). As traditional researcher, researchers expected themselves 
Table 4 Relationships between the different roles of researchers

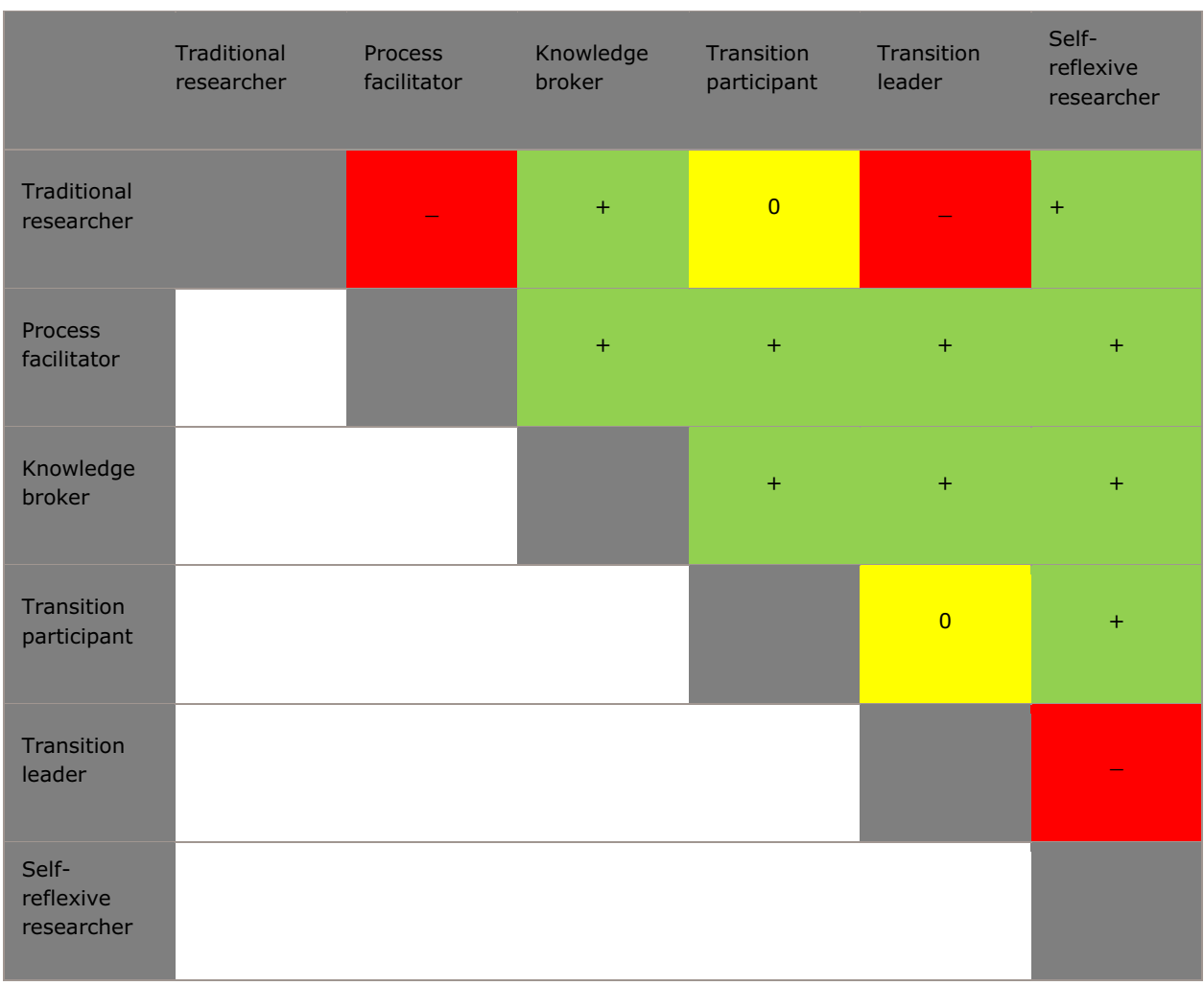

Green boxes $(+)$ indicate that two roles could be combined without problems, yellow boxes $(0)$ indicate that special care was needed to combine these roles, red boxes (-) indicate a conflicting combination to gain new knowledge to add to a body of scientific literature. Participants, on the other hand, were more interested in practical applications of the work of researchers, which is more reflected in roles such as knowledge broker, transition participant and transition leader. Look, there is always a tension, especially when you are working with knowledge institutes, between knowledge production and applicability (Practice). Similar to the Dutch Ecogenomics Consortium analysed by Kloet et al. (2012), researchers also felt a discrepancy between what participants in KAP Water expected from them and expectations of the academic community, and more directly their employers, to generate new knowledge and publish articles in their roles as traditional researcher and knowledge broker. With reflexivity being a central part of KAP Water, researchers adopted the role of self-reflexive researchers and continuously reflected on their position as a researcher within the programme.

We found that some roles could be combined without problems while other combinations created internal conflicts. The green boxes in Table 4 show non-conflictual roles: roles that could be combined without problems. Process facilitators were often also knowledge brokers, transition participants and transition leaders mediating between different types of knowledge and participating or leading in the process of defining new governance approaches. These roles combine relatively easily in practice. The role of knowledge broker was the only role researchers could easily combine with any other role, most naturally with their role as traditional researcher where they could connect scientific knowledge to practice. But also in more engaged roles as transition leader and transition participant where knowledge brokerage was requested both by other researchers as well as by actors from practice, for example in the form of sharing and synthesizing scientific insights to address real-life problems.

Moreover, process facilitators in KAP Water were also expected to perform activities related to their role as traditional researcher; documenting new knowledge and making knowledge available by publishing about it. In practice, it turned out to be difficult to combine all these roles. Right now as a researcher you are so involved in the process, you are facilitating and also experiencing so it is not possible to simultaneously occupy yourself with knowledge [production] (Research). This illustrates how researchers were often quite capable of adopting most roles individually, but that the combination of multiple roles at once proved to be difficult.

However, we also found that some roles could not be easily combined. Roles of researchers conflicted for practical reasons such as being so busy facilitating as a process facilitator that there is not enough time to document knowledge as a traditional researcher or not being able to 'justify' certain activities to their home institute. But roles conflicted on a more fundamental level as well. As transition leaders and 
transition participants, researchers committed themselves to (normative) goals of the programme and actively contributed to formulating desired future scenarios and working towards these scenarios. This conflicts with a role as a neutral and objective traditional researcher. Combining transition leader and transition participant needed extra care, because as transition participant researchers aimed to participate in ongoing processes of change, while as transition leader they simultaneously aimed to adopt a more leading role to motivate and empower participants. This needed some balancing between participation in ongoing processes on the one hand and taking the lead in (new) processes on the other hand.

As self-reflexive researchers, researchers reflected on this normativity and were therefore aware of their position in the process. Our case suggests that the role of self-reflexive researcher can be combined with most of the other roles. Only the role of transition leader has conflicted with this role, at times when the transition leader is so fully occupied with managing the processes and providing guidance to the other participants, that there is insufficient mental space available for reflexivity. Balancing action and reflection, and especially the reflection in action, has to be learnt through practicing transition leadership. Different researchers had different experiences with combining self-reflexivity and a role as transition leader. This indicates that the ability to combine certain roles also depends on experience, personality traits and skills of researchers.

Among the various researchers involved in KAP Water, we observe a division between researchers who were more action-oriented (often adopting a role as process facilitator among other roles) and researchers who were more knowledge-oriented. One implication of this rather natural distinction is that there was not always sufficient contact between the action-oriented and the more knowledge-oriented activities of the programme, and the knowledge developed did not always correspond with the most topical issues in practice.

\section{Discussion}

Our results show that researchers in process-oriented transdisciplinary research experience tensions between different roles. Looking at our results and collectively reflecting on our experiences as researchers within KAP Water, these tensions seem to arise from three underlying sources: (1) researchers' self-perception and expectations; (2) expectations of transdisciplinary partners, funders and researchers' home institutions and (3) societal convictions about what scientific knowledge is and how it should be developed.

The first source of tension is the researcher's self-perception and expectations. Wittmayer and Schäpke (2014) identified four key issues for researchers in action-oriented approaches to sustainability research: ownership, sustainability, power and action. These issues relate to expectations about the researchers' identity: who am I as a researcher and what expectations do I have to meet in process-oriented transdisciplinary programmes? Broadening the repertoire of roles and research strategies can challenge the identity of researchers, as (combinations of) roles can be conflicting. Moreover, more engaged roles in transdisciplinary sustainability research require new skills and competences that researchers are often not trained in (Wiek et al. 2011). This challenges researchers' self-perception and expectations as they now need skills that are sometimes difficult to combine with 'traditional' skills linked to neutral and objective providers of knowledge.

The second source of tension concerns what others expect from researchers. Given the inherent uncertainty in sustainability transitions, policy makers and public authorities in our case hoped to find certainty in scientific research ('state of the art' science (Scholz and Steiner 2015a)). For instance, a clear-cut answer to the question which solution could be considered 'the most sustainable'. Even where researchers acknowledged uncertainties and incompleteness of different forms of knowledge (Scholz and Steiner 2015b), their partners did not always agree. Moreover, transition participants and transition leaders experienced a 'struggle for relevance' (Hessels et al. 2011): while their home institutions expected them to deliver 'typical academic' products, funders expected more and, above all, quickly delivered 'readily applicable outputs'.

Third, these tensions relate to societal concepts of what scientific knowledge is and how this is developed and taught. Although publications on transdisciplinarity abound, there is still a need for reflection and theory development to be built on the practice of transdisciplinary processes (Scholz and Steiner 2015b). Here we experience the epistemological barrier noted by Benard and de Cock-Buning (2014) of recognising the relevance of experiential knowledge. When and by whom is knowledge resulting from a systematic process of inquiry in a transdisciplinary team accepted as "scientific' (Ruddle 2000)? What quality criteria need to be met to ensure that co-produced knowledge adequately integrates scientific and experiential knowledge to formulate 'socially accepted options for solutions that acknowledge uncertainties' that are simultaneously considered to be state-of-the-art science based (Scholz and Steiner 2015a)? The guidelines proposed by Jahn and Keil (2015), in particular, the distinction between the quality of the research problems, the process, and the results, can help to assure the quality of transdisciplinary research. A remaining challenge is how to translate these quality criteria into the evaluation systems of the home institutions of the transdisciplinary researchers. Our analysis confirms that these tend to reward the more traditional roles more than the action-oriented roles. Although many transdisciplinary researchers feel part of an 
international transdisciplinary community, their careers typically depend on disciplinary organisation structures.

\section{Conclusion and implications}

Process-oriented or transdisciplinary research approaches are a promising strategy for researchers to contribute to sustainability transitions (Miller 2013; Wiek et al. 2012), in which social scientists have an important part to play. Such approaches require researchers to broaden their repertoire of roles and research strategies, which may challenge their identities as researchers. This contributes to the literature by enhancing our understanding of the interactions and tensions between roles of researchers in transdisciplinary research.

Our analysis confirms that roles of researchers can change over time (Hilger et al. 2018; Wiek 2007; Wittmayer and Schäpke 2014). KAP Water researchers adjusted their roles from reflective scientists to more action-oriented roles (transition participants or even leaders). We also found that some roles can be combined or integrated. However, we found conflicting relationships between the roles of traditional researcher and transition participant, traditional researcher and transition leader and between transition leader and selfreflexive participant. In summary, these observations suggest a tension between knowledge and action: it proved difficult to combine action-oriented (engaged) roles with knowledgeoriented roles.

On a practical level, researchers run into limitations in time and space. They can only conduct a certain number of tasks in the time available for a particular programme. The natural rhythm of action work also tends to be faster than that of traditional research. Moreover, researchers cannot take detailed notes when simultaneously being intensively engaged in stakeholder processes. On a more fundamental level, researchers struggle with their normative position. Researchers may feel that committing themselves explicitly to the normative goals of a programme reduces their credibility as neutral and objective providers of knowledge in this particular domain. From a constructivist perspective, however, researchers will never be fully objective, because all scientific practices include normative considerations (Scholz 2017). Literature on post-normal science and Mode 2 knowledge production argues that researchers can take a normative position and at the same time produce reliable knowledge by exercising norms like integrity, social accountability and reflexivity (Funtowicz and Ravetz 1993; Nowotny et al. 2001).

Although previous studies have identified that researchers can struggle with these different roles (Hilger et al. 2018; Pohl et al. 2010), they did not yet highlight this fundamental tension explicitly. Wittmayer and Schäpke indicated that the role of 'change agent' was the most challenging to fulfil, but did not elaborate on the interactions or tensions with other roles (Wittmayer and Schäpke 2014). Similar to the observations by (Hilger et al. 2018), we found that researchers tend to adopt non-traditional, more engaged roles (such as process facilitator or transition leader) when practitioners involved have limited time and resources to take on these roles and when there is lack of a functioning project group. The current paper therefore enhances our understanding of interactions and tensions between different roles for researchers in transdisciplinary sustainability research, which remained unexplored in previous transdisciplinary research.

Following these findings, we discuss three implications of this study. The first two implications relate to organising transdisciplinary programmes, while the third elaborates on implications for education.

First, tensions with regards to new roles and expectations can be anticipated on in the programme design (Hessels et al. 2018), by dividing conflicting roles over different researchers. By being transparent about competences of researchers, appropriate divisions of roles can be chosen. Similarly, in the programme design researcher can avoid combining conflicting roles in one person. Process-oriented research demands a well-balanced team with a suitable composition in terms of skills, competences, qualifications and status required for certain roles (Hilger et al. 2018). Given a particular researcher's personal characteristics, disciplinary background and epistemological orientation, some roles will fit easier than others. The more actively a researcher engages with sustainability transitions, the more researchers may need to give up the authority associated with traditional 'Mode 1' knowledge production (Hessels and Van Lente 2008) and acknowledge that their own epistemic authority is just one source of knowledge among many others (Miller 2013). Merely acknowledging that researchers can take up different roles in transdisciplinary processes and that each of these possible roles has its own merits and implications, might already ease some of the tensions.

Second, by explicitly articulating expectations of different actors (academic and non-academic) in the programme design and agreeing on a fruitful approach for the programme, researchers can avoid having to deal with partners or funders with unrealistic expectations about the (combination of) roles of researchers (Pohl and Hadorn 2007). Comprehending early context-specific perspectives of stakeholders can assist the project in understanding collective expectations for the course of a project and provide concrete goals and values that can be applied as a starting point for observing and understanding change (Thompson et al. 2017). Moreover, it is important to realise that tensions in transdisciplinary programmes are not the result of shortcoming of individuals or processes, but rather a result of a larger change in research culture. Therefore, it is important 
to identify and address tensions and conflicting expectations explicitly in project teams (Thompson et al. 2017).

Third, this paper raised the question how to train future academic professionals to better equip them for the challenges of sustainability transition research. Most researchers active in the Knowledge-Action programme on Water were originally trained in the descriptive-analytical mode of science. While some felt it appropriate and were comfortable to adopt more engaged roles and intervene in the innovation process, others felt that they should be more distanced and hold on to their role as neutral observers and knowledge providers. Higher education institutions that want to prepare students for transdisciplinary process-oriented research, should address:

1. how to integrate knowledge and action. Offering students 'real-world' learning opportunities, introduces them to collaborative research and knowledge co-creation (Fadeeva et al. 2010).

2. teaching new skills and competencies to be able to make valuable contributions to transdisciplinary sustainability research. This paper confirms the value of the five key competences for sustainability identified by Wiek et al. (2011): systems-thinking competence, anticipatory competence, normative competence, strategic competence and interpersonal competence. Additionally, future academic professionals should be taught more practical skills such as facilitation, reflection or mediation, that are needed to be able to properly adopt different roles.

3. reflexivity: reflections on own (normative) assumptions and the competency to consciously switch between roles. The roles for researchers as described in this paper are ideal-types that will overlap and will be combined in reality. To deal with changing circumstances, routines or assumptions, researchers will adopt different roles. The key competences formulated by Wiek et al. (2011) will support researchers in fulfilling their different roles, but they will not immediately help researchers in combining different roles or switching between them. Education can stimulate students to be reflective about their intentions as researchers. After all, it depends on these intentions which roles they should adopt (Hilger et al. 2018).

This paper has addressed the complex issue of balancing knowledge and action in transdisciplinary research. Based on an analysis of the experiences of researchers in a specific process-oriented programme, we hope to provide some guidance in dealing with conflicting roles of researchers. The process of writing this paper has been an interesting experience for the authors, since it instigated discussions about our own roles and views. These reflexive discussions were indicative of the search that many researchers experience in how to balance and combine different roles, and how to relate to diverging expectations about appropriate roles. Informed by our personal experience, we want to stress that the existence of tensions described in this paper is not necessarily a problem. On the contrary, discussing and addressing these tensions can foster creativity and keep researchers on their toes regarding their positionality.

Supplementary Information The online version contains supplementary material available at https://doi.org/10.1007/s11625-021-00938-7.

Acknowledgements The authors thank all interviewees for their time and openness. Moreover, we thank Casper van Splunter for contributing to data collection, and Annaliesa Hilger, Boelie Elzen, and several interview respondents for comments on an earlier draft. We also thank the Regional Public Water Authority Amstel, Gooi en Vecht for their openness and support.

Open Access This article is licensed under a Creative Commons Attribution 4.0 International License, which permits use, sharing, adaptation, distribution and reproduction in any medium or format, as long as you give appropriate credit to the original author(s) and the source, provide a link to the Creative Commons licence, and indicate if changes were made. The images or other third party material in this article are included in the article's Creative Commons licence, unless indicated otherwise in a credit line to the material. If material is not included in the article's Creative Commons licence and your intended use is not permitted by statutory regulation or exceeds the permitted use, you will need to obtain permission directly from the copyright holder. To view a copy of this licence, visit http://creativecommons.org/licenses/by/4.0/.

\section{References}

Adelle C, Pereira L, Görgens T, Losch B (2019) Making sense together: The role of scientists in the coproduction of knowledge for policy making. Science and Public Policy

Becker E (2002) Transformations of social and ecological issues into transdisciplinary research. Knowl Sustain Dev Insight Encycl Life Sup Syst 3:949-963

Benard M, de Cock-Buning T (2014) Moving from monodisciplinarity towards transdisciplinarity: insights into the barriers and facilitators that scientists faced. Sci Public Policy 41(6):720-733

Boon WP, Chappin MM, Perenboom J (2014) Balancing divergence and convergence in transdisciplinary research teams. Environ Sci Policy 40:57-68

Boon WPC, Hessels LK, Horlings E (2019) Knowledge co-production in protective spaces: case studies of two climate adaptation projects. Reg Environ Change:1-13

Bromham L, Dinnage R, Hua X (2016) Interdisciplinary research has consistently lower funding success. Nature 534(7609):684

Brouwer S, Büscher C, Hessels LK (2017) Towards transdisciplinarity: a water research programme in transition. Sci Public Policy 45(2):211-220

Charmaz K, Belgrave L (2012) Qualitative interviewing and grounded theory analysis. SAGE Handb Inter Res Comp Craft 2:347-365

Cornell S, Berkhout F, Tuinstra W et al (2013) Opening up knowledge systems for better responses to global environmental change. Environ Sci Policy 28:60-70

Dewulf A, Craps M, Bouwen R, Taillieu T, Pahl-Wostl C (2005) Integrated management of natural resources: dealing with ambiguous 
issues, multiple actors and diverging frames. Water Sci Technol 52(6): 115-124

Fadeeva Z, Mochizuki Y, Brundiers K, Wiek A, Redman CL (2010) Real-world learning opportunities in sustainability: from classroom into the real world. Int J Sustain High Edu

Frantzeskaki N, De Haan H (2009) Transitions: two steps from theory to policy. Futures 41(9):593-606

Frantzeskaki N, Loorbach D, Meadowcroft J (2012) Governing societal transitions to sustainability. Int J Sustain Dev 15(1-2):19-36

Funtowicz SO, Ravetz JR (1993) Science for the post-normal age. Futures 25(7):739-755

Grin J, Rotmans J, Schot J (2010) Transitions to sustainable development: new directions in the study of long term transformative change. Routledge

Hadorn GH, Bradley D, Pohl C, Rist S, Wiesmann U (2006) Implications of transdisciplinarity for sustainability research. Ecol Econ 60(1):119-128

Hegger D, Lamers M, Van Zeijl-Rozema A, Dieperink C (2012) Conceptualising joint knowledge production in regional climate change adaptation projects: success conditions and levers for action. Environ Sci Policy 18:52-65

Hessels LK, Van Lente H (2008) Re-thinking new knowledge production: a literature review and a research agenda. Res Policy 37(4):740-760

Hessels LK, van Lente H, Grin J, Smits REHM (2011) Changing struggles for relevance in eight fields of natural science. Ind High Educ 25(5):347-357

Hessels LK, de Jong SPL, Brouwer S (2018) Collaboration between heterogeneous practitioners in sustainability research: a comparative analysis of three transdisciplinary programmes. Sustainability 10(12):4760

Hevner AR (2007) A three cycle view of design science research. Scand J Inf Syst 19(2):4

Hilger A, Rose M, Wanner M (2018) Changing faces-factors influencing the roles of researchers in real-world laboratories. GAIA-Ecol Perspect Sci Soc 27(1):138-145

Hoes A-C, Regeer BJ, Bunders JFG (2008) TransFormers in knowledge production: building science-practice collaborations. Act Learn Res Pract 5(3):207-220

Hsieh H-F, Shannon SE (2005) Three approaches to qualitative content analysis. Qual Health Res 15(9):1277-1288

Jahn T, Keil F (2015) An actor-specific guideline for quality assurance in transdisciplinary research. Futures 65:195-208

Jahn T, Bergmann M, Keil F (2012) Transdisciplinarity: between mainstreaming and marginalization. Ecol Econ 79:1-10

Jolibert C, Wesselink A (2012) Research impacts and impact on research in biodiversity conservation: the influence of stakeholder engagement. Environ Sci Policy 22:100-111

Kemmis S (2009) Action research as a practice-based practice. Edu Act Res 17(3):463-474

Klein JT (2004) Prospects for transdisciplinarity. Futures 36(4):515-526

Kloet RR, Hessels LK, Zweekhorst MBM, Broerse JEW, de Cock BT (2012) Understanding constraints in the dynamics of a research programme intended as a niche innovation. Sci Pub Pol 40(2):206-218

Lang DJ, Wiek A, Bergmann $M$ et al (2012) Transdisciplinary research in sustainability science: practice, principles, and challenges. Sustain Sci 7(1):25-43

Loorbach D (2010) Transition management for sustainable development: a prescriptive, complexity-based governance framework. Governance 23(1):161-183

Maag S, Alexander TJ, Kase R, Hoffmann S (2018) Indicators for measuring the contributions of individual knowledge brokers. Environ Sci Policy 89:1-9
Markard J, Raven R, Truffer B (2012) Sustainability transitions: an emerging field of research and its prospects. Res Policy 41(6):955-967

Mayring P (2004) Qualitative content analysis. Compan Qual Res 1(2004):159-176

Menken S, Keestra M (2016) An introduction to interdisciplinary research: theory and practice. Amsterdam University Press

Miller TR (2013) Constructing sustainability science: emerging perspectives and research trajectories. Sustain Sci 8(2):279-293

Mollinga PP (2009) Towards the transdisciplinary engineer: Incorporating ecology, equity and democracy concerns into water professionals' attitudes, skills and knowledge. Irrig Drain 58(S2):S195-S204

Nowotny H, Scott P, Gibbons M (2001) Re-thinking science: knowledge and the public in an age of uncertainty. Polity Press, Cambridge

Pohl C, Hadorn GH (2007) Principles for designing transdisciplinary research. Oekom Munich

Pohl C, Rist S, Zimmermann A et al (2010) Researchers' roles in knowledge co-production: experience from sustainability research in Kenya, Switzerland, Bolivia and Nepal. Sci Pub Pol 37(4):267-281

Polk M (2015) Transdisciplinary co-production: designing and testing a transdisciplinary research framework for societal problem solving. Futures 65:110-122

Rafols I, Leydesdorff L, O'Hare A, Nightingale P, Stirling A (2012) How journal rankings can suppress interdisciplinary research: a comparison between innovation studies and business and management. Res Policy 41(7):1262-1282

Regeer BJ (2009) Making the invisible visible. Analysing the development of strategies and changes in knowledge production to deal with persistent problems in sustainable development

Ruddle K (2000) Systems of knowledge: dialogue, relationships and process. Environ Dev Sustain 2(3):277-304

Scholz RW (2017) The normative dimension in transdisciplinarity, transition management, and transformation sciences: new roles of science and universities in sustainable transitioning. Sustainability 9(6):991

Scholz RW, Steiner G (2015a) The real type and ideal type of transdisciplinary processes: part I-theoretical foundations. Sustain Sci 10(4):527-544

Scholz RW, Steiner G (2015b) Transdisciplinarity at the crossroads. Sustain Sci 10(4):521-526

Schut M, van Paassen A, Leeuwis C, Klerkx L (2013) Towards dynamic research configurations: a framework for reflection on the contribution of research to policy and innovation processes. Sci Pub Pol 41(2):207-218

Segrave AJ (2014) Time to change: the foreseeable future for water planning.

Stock P, Burton RJF (2011) Defining terms for integrated (multiinter-trans-disciplinary) sustainability research. Sustainability 3(8):1090-1113

Swann Jr WB, Bosson JK (2008) Identity negotiation: a theory of self and social interaction.

Thomas DR (2003) A general inductive approach for qualitative data analysis.

Thompson MA, Owen S, Lindsay JM, Leonard GS, Cronin SJ (2017) Scientist and stakeholder perspectives of transdisciplinary research: early attitudes, expectations, and tensions. Environ Sci Policy 74:30-39

Van Rijnsoever FJ, Hessels LK (2011) Factors associated with disciplinary and interdisciplinary research collaboration. Res Pol 40(3):463-472

Walter AI, Helgenberger S, Wiek A, Scholz RW (2007) Measuring societal effects of transdisciplinary research projects: design 
and application of an evaluation method. Eval Program Plann 30(4):325-338

Wiek A (2007) Challenges of transdisciplinary research as interactive knowledge generation-experiences from transdisciplinary case study research. GAIA-Ecol Perspect Sci Soc 16(1):52-57

Wiek A, Lang DJ (2016) Transformational sustainability research methodology. Sustain Sci Springer: 31-41

Wiek A, Withycombe L, Redman CL (2011) Key competencies in sustainability: a reference framework for academic program development. Sustain Sci 6(2):203-218

Wiek A, Ness B, Schweizer-Ries P, Brand FS, Farioli F (2012) From complex systems analysis to transformational change: a comparative appraisal of sustainability science projects. Sustain Sci $7(1): 5-24$
Wittmayer JM, Schäpke N (2014) Action, research and participation: roles of researchers in sustainability transitions. Sustain Sci 9(4):483-496

Wittmayer JM, Avelino F, van Steenbergen F, Loorbach D (2017) Actor roles in transition: Insights from sociological perspectives. Environmental Innovation and Societal Transitions 24:45-56

Zuiderent-Jerak T (2015) Situated intervention: Sociological experiments in health care. MIT Press

Publisher's Note Springer Nature remains neutral with regard to jurisdictional claims in published maps and institutional affiliations. 